\title{
Numerical Simulation on Ice Shedding Phenomena in Turbomachinery
}

\author{
Ryosuke Hayashi $^{1}$ and Makoto Yamamoto ${ }^{2}$ \\ 1. Graduate School of Mechanical Engineering, Tokyo University of Science, Tokyo 125-8585, Japan \\ 2. Department of Mechanical Engineering, Tokyo University of Science, Tokyo 125-8585, Japan
}

Received: October 01, 2014 / Accepted: November 03, 2014 / Published: January 31, 2015.

\begin{abstract}
In the jet engine, icing phenomena occur primarily on the fan blades, the FEGVs (fan exit guide vanes), the splitter, and the low-pressure compressor. Accreted ice disturbs the inlet flow and causes large energy losses. In addition, ice accreted on a fan rotor can be shed from the blade surface due to centrifugal force and can damage compressor components. This phenomenon, which is typical in turbomachinery, is referred to as ice shedding. Although existing icing models can simulate ice growth, these models do not have the capability to reproduce ice shedding. In the present study, we develop an icing model that takes into account both ice growth and ice shedding. Furthermore, we have validated the proposed ice shedding model through the comparison of numerical results and experimental data, which include the flow rate loss due to ice growth and the flow rate recovery due to ice shedding. The simulation results for the time at which ice shedding occurred and what were obtained using the proposed ice shedding model were in good agreement with the experimental results.
\end{abstract}

Key words: Ice accretion, ice shedding, turbomachinery, multiphysics CFD (computational fluid dynamics).

\section{Nomenclature}

$A_{\text {cell }} \quad$ Area of surface cell

$A_{\text {in }} \quad$ Area of inlet droplet

$C_{D} \quad$ Drag coefficient

$E_{a c} \quad$ Energy of accreted ice

$E_{\text {air }} \quad$ Energy of aerodynamics

$E_{c o n} \quad$ Energy of convection

$E_{e, s} \quad$ Energy of evaporation or sublimation

$E_{f r i} \quad$ Energy of friction

$E_{i m} \quad$ Energy of impinging droplet

$E_{\text {in }} \quad$ Energy of runback-in

$E_{\text {out }} \quad$ Energy of runback-out

$F_{a} \quad$ Adhesion force between ice and the wall

$F_{c} \quad$ Centrifugal force acting on accreted ice

$f \quad$ Freezing fraction

$d_{d} \quad$ Droplet diameter

$L W C \quad$ Liquid water content

$m_{a c} \quad$ Mass of accreted ice

$m_{e, s} \quad$ Mass of evaporation or sublimation

$m_{i m} \quad$ Mass of impinging droplet

$m_{\text {in }} \quad$ Mass of runback-in

Corresponding author: Ryosuke Hayashi, Ph.D. student, research fields: CFD and Jet Engine. E-mail: j4512703@ed.tus.ac.jp.

$\begin{array}{ll}m_{\text {out }} & \text { Mass of runback-out } \\ M V D & \text { Median volume diameter } \\ N_{\text {com }} & \text { Total number of computational droplets } \\ N_{\text {im }} & \text { Local number of impingement droplets } \\ N_{\text {in }} & \text { Number of inflow droplets } \\ Q_{i n} & \text { Mass flow rate of inflow droplets } \\ P_{\text {im }} & \text { Local rate of impingement droplets } \\ \operatorname{Re}_{d} & \text { Reynolds number of droplet } \\ r_{d} & \text { Radial position of droplet } \\ t & \text { Time } \\ U_{d} & \text { Droplet velocity } \\ U_{f} & \text { Flow velocity } \\ U_{i n} & \text { Inlet droplet velocity } \\ U_{r} & \text { Relative velocity between air and droplet } \\ V_{d} & \text { Droplet volume } \\ \beta & \text { Local water distribution } \\ \rho_{d} & \text { Droplet density } \\ \rho_{f} & \text { Flow density } \\ \tau & \text { Adhesion stress } \\ \Omega & \text { Rotational speed }\end{array}$

\section{Introduction}

At altitudes in which aircraft operates, clouds contain numerous super-cooled droplets, which impinge 
and accrete on an aircraft body. This phenomenon is referred to as ice accretion. When an ice layer forms on an aircraft wing, the ice adversely affects the performance of the aircraft by increasing drag and reducing lift and may cause a crash. In a jet engine, ice accretion disturbs the inlet flow and can lead to severe performance degradation. Thus, ice accretion phenomena are a serious problem in aircraft operations. In order to overcome the problems associated with icing, a number of major research institutes around the world, including NASA (National Aeronautics and Space Administration) and ONERA (Office National d'Etudes et de Recherches Aerospatiales) have been investigating ice accretion phenomena both experimentally and computationally [1-4].

The icing phenomenon is caused by complicated interactions under various physical conditions, including the ambient temperature, the LWC (liquid water content), the temperature of the surface with which the droplets collide, the impingement position, the surface roughness, and the mass of the droplets. Generally, it is difficult to reproduce these complicated icing conditions experimentally. In addition, icing tests are costly. Therefore, CFD (computational fluid dynamics) is expected to provide a useful method by which to predict ice accretion phenomena, because of the rapid development of computers in recent years. Various icing simulations can be conducted through two-dimensional simulations using a NACA (National Advisory Committee for Aeronautics) airfoil for three-dimensional simulations of a jet engine [5-8].

Icing of the main wing and the tail wing have been investigated for more than 60 years, and de/anti-ice systems, such as de-icer boots and bleed air systems, have been proposed and are widely used in existing aircraft. However, practical de/anti-icing systems for jet engine icing have not yet been established. In a jet engine, the main icing components are the fan blade, the FEGV (fan exit guide vane), the nose cone, the splitter, and the low-pressure compressor. In addition, there have recently been instances of icing on high-pressure compressors, in which the temperature is approximately $30{ }^{\circ} \mathrm{C}$ [9]. Based on the above considerations, icing phenomena in a jet engine have been actively investigated in recent days [10].

Engine icing leads to ice shedding, which is a phenomenon whereby accreted ice is shed from the wall surface. After ice shedding occurs, the jet engine injects the shed ice pieces, which damage the internal components, including the compressor blade and the casing. This phenomenon is very complicated because there are several unknown physical properties, such as the ice density, the adhesion force between accreted ice and the wall, and the contact force between ice pieces. Papadakis et al. [11] measured the aerodynamics forces and moments acting on a fragment similar to a piece of ice at a wind tunnel facility and simulated the trajectory of the shed fragment based on the data obtained from the wind tunnel test. Baruzzi et al. [12] considered a fluid-structure interaction on cube ice and solved the flying cube movement. However, they considered only shed ice pieces and ignored ice growth and factors affecting ice shedding.

Existing icing models can reproduce only ice growth and do not include ice shedding. Therefore, existing icing models have a problem in that accreted ice is assumed to grow continuously with time.

In the present study, we develop a new icing model that can consistently reproduce the flow field around the computational target, super-cooled droplets impinging on the walls, ice growth, and ice shedding. The proposed icing model, which includes ice shedding, is validated though comparison with experimental data for flow rate change due to ice growth and ice shedding, as measured by Murooka et al. [13].

\section{Numerical Procedures}

The icing simulation code used herein includes iterative computations for the fluid motion, the droplet trajectory, the ice growth, the ice shedding and the grid modification. Each computation is described below in detail. 


\subsection{Flow Field}

The flow field is assumed to be three-dimensional, compressible, and turbulent. The governing equations are the Favre-averaged continuity, Navier-Stokes, and energy equations. Since a rotational frame of reference is used, the Coriolis force and centrifugal force are added as body forces. The Kato-Launder $k$-turbulence model (Kato and Launder [14]) is used to estimate turbulence. The governing equations are discretized using a second-order upwind TVD (total variation diminishing) scheme (Yee [15]) for the inviscid terms, a second-order central difference scheme for the viscous terms, and an LU-ADI (lower upper-alternating direction implicit) scheme (Fujii and Obayashi [16]) for the time integration.

\subsection{Droplet Trajectory}

Droplet trajectory is computed based on a Lagrangian approach in order to obtain the local water distribution on a blade. The computation uses the following assumptions:

(1) Droplets are spherical;

(2) Droplets are sufficiently small and thus do not break up;

(3) The forces acting on a droplet are drag, centrifugal force, and the Coriolis force;

(4) Droplets do not interact with each other;

(5) Droplets do not affect the flow field (one-way coupling);

(6) The initial droplet velocity is equal to the gas velocity at the release point.

The equation of the droplet motion is:

$$
\begin{aligned}
\frac{\mathrm{d} \vec{U}_{d}}{\mathrm{~d} t} & =\frac{3}{4} C_{D} \frac{\rho_{f}}{\rho_{d}} \frac{1}{d_{d}} \vec{U}_{r}\left|\vec{U}_{r}\right| \\
& -\left\{2 \vec{\Omega} \times \vec{U}_{d}-\vec{\Omega} \times\left(\vec{\Omega} \times \vec{r}_{d}\right)\right\}
\end{aligned}
$$

The second term on the right-hand-side represents the centrifugal force and the Coriolis force. The drag coefficient $C_{D}$ is expressed as:

$$
C_{D}=\frac{24}{R e_{d}}\left(1+0.15 R e_{d}{ }^{0.687}\right)
$$

where, $R e_{d}$ is the Reynolds number of a droplet based on the diameter and the relative velocity between the gas and the droplet.

The droplet trajectory is computed in order to obtain the local water distribution, i.e., the impingement distribution of super-cooled droplets on a unit area at each second. The mass flow rate of the inflow droplet in the control volume $Q_{i n}$ is as:

$$
Q_{\text {in }}=A_{\text {in }} U_{\text {in }} L W C
$$

The number of inflow droplets per second $N_{\text {in }}$ is computed as:

$$
N_{i n}=\frac{Q_{i n}}{\rho_{d} V_{d}}
$$

The local ratio of the number of impinging droplets to the total number of droplets $P_{i m}$ and the local water distribution $\beta$ are expressed, respectively, as:

$$
\begin{aligned}
& P_{i m}=\frac{N_{i m}}{N_{\text {com }}} \\
& \beta=P_{\text {im }} \frac{N_{\text {in }}}{A_{\text {cell }}}
\end{aligned}
$$

The local water distribution is a key parameter in icing simulation.

\subsection{Thermodynamics}

The thermodynamic computation is carried out using the Messinger model proposed by Messinger [17]. Fig. 1 shows an image of the Messinger model, which is based on the mass and the energy balances in a control volume. The governing equations are:

$$
\begin{gathered}
m_{\text {im }}+m_{\text {in }}=m_{a c}+m_{e, s}+m_{\text {out }} \\
E_{\text {im }}+E_{\text {in }}+E_{\text {air }}+E_{\text {fri }}=E_{a c}+E_{e, s}+E_{\text {out }}+E_{c o n}
\end{gathered}
$$

The freezing rate $f$ and the runback-out mass $m_{\text {out }}$ can be derived from Eqs. (7) and (8) as:

$$
\begin{gathered}
f=\frac{m_{a c}}{m_{\text {im }}+m_{\text {in }}} \\
m_{\text {out }}=(1-f)\left(m_{\text {im }}+m_{\text {in }}\right)-m_{e, s}
\end{gathered}
$$

If $f=1$, all of the mass in the control volume accretes, 


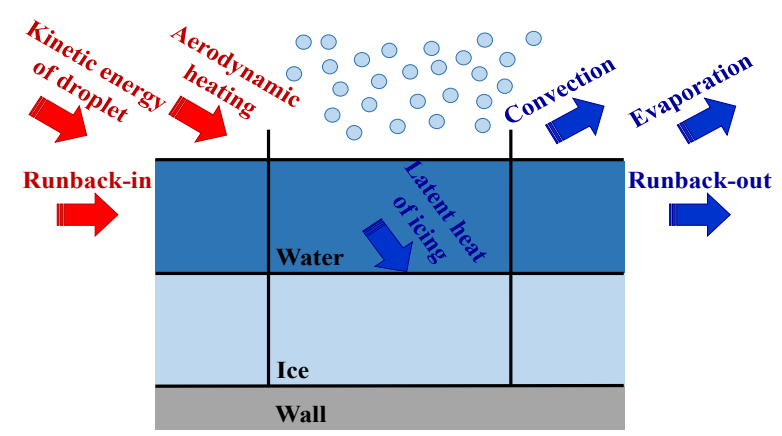

Fig. 1 Schematic diagram of the Messinger model.

whereas, if $f=0$, all of the mass in the control volume runs back to the next cell.

\subsection{Grid System to Reproduce the Ice Layer}

In icing simulations, computational grid regeneration is required with the surface shape change due to accreted ice. In the previous simulation method [8], we regenerated the computational grid along the ice surface. This requires practical experience and know-how when the ice geometry is complicated. In the present study, the exposure time is long enough for the ice shedding phenomenon to occur. In addition, the ice geometry after ice shedding is very complicated. Thus, the grid regeneration used in the previous method is too difficult. In order to overcome this problem, we adopt the icing cell method (see Fig. 2), which is a new method for simulating the ice shedding phenomenon. In this method, the computational cells are classified as either a fluid cell or an ice cell. If accreted ice grows over a fluid cell, the cell is treated as an ice cell, and the ice cell is retreated as a fluid cell after ice shedding occurs. Therefore, unlike in the previous method, the icing cell method does not need to regenerate the computational grid along the accreted ice shape. Thus, we can reproduce both the ice growth and the ice shedding.

\subsection{Ice Shedding Judgment}

In turbomachinery, such as a fan rotor, ice shedding occurs when the centrifugal force increases due to the growth of thick ice. Forces acting on ice accreted on the

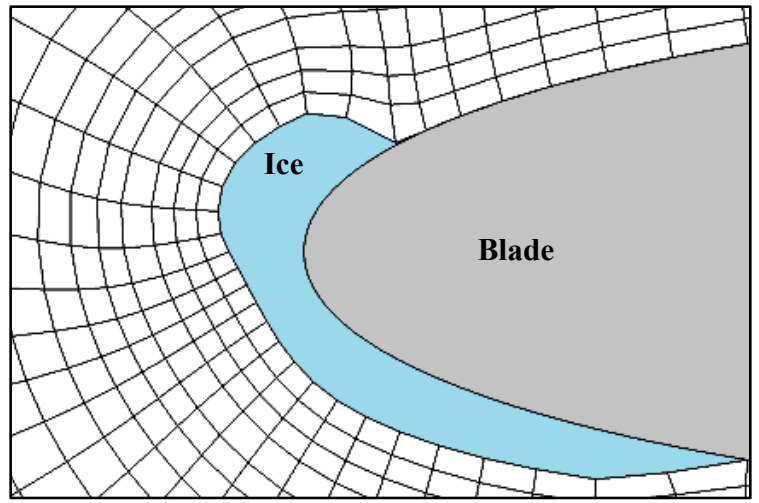

(a) Previous method

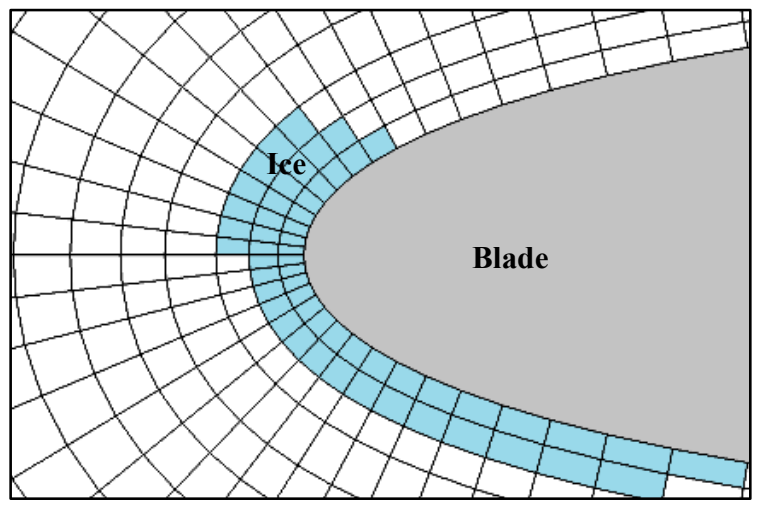

(b) Icing cell method

Fig. 2 Grid systems for reproducing the ice layer.

rotor surface include the adhesion force between the accreted ice and the wall, the centrifugal force, the contact force between the ice pieces, the fluid drag, and the wind shear stress. Since the fluid drag and the wind shear stress are much smaller than the other terms (approximately three orders of magnitude), these terms can be ignored. Simulation of the ice contact force is very difficult, because there is poor understanding of this force. Therefore, we simplify the ice-shedding phenomenon and treat both the ice adhesion force and the centrifugal force as the force acting on the accreted ice. We attempt to reproduce the ice shedding phenomenon under this simplified assumption. The centrifugal force and the adhesion force acting on accreted ice are expressed, respectively, as:

$$
\begin{gathered}
F_{c}=\rho_{i} A_{\text {cell }} B_{i} r \Omega^{2} \\
F_{a}=\tau A_{\text {cell }}
\end{gathered}
$$


Table 1 Computational conditions for validation.

\begin{tabular}{lll}
\hline Airfoil type & Unit & NACA0012 \\
\hline Chord length & $(\mathrm{m})$ & 0.53 \\
Angle of attack & $(\mathrm{deg})$. & 4.0 \\
Median volume diameter & $(\mu \mathrm{m})$ & 20 \\
Liquid water content & $\left(\mathrm{g} / \mathrm{m}^{3}\right)$ & 1.30 \\
Exposure time & $(\mathrm{s})$ & 480 \\
Free stream velocity & $(\mathrm{m} / \mathrm{s})$ & 58.1 \\
Static pressure & $(\mathrm{kPa})$ & 95.61 \\
Static temperature & $\left({ }^{\circ} \mathrm{C}\right)$ & -27.8 \\
\hline
\end{tabular}

In Eq. (12), the adhesion stress $\tau$ is obtained from an ice adhesion test conducted by Murooka et al. [13] The wall material is aluminum. By use of Eqs. (11) and (12), we computed the forces acting on the accreted ice on each blade surface cell. If the centrifugal force exceeds the adhesion force, we judge ice shedding to have occurred and treat the cell as a shedding cell (i.e., fluid cell). Using the rotorcraft, Brouwers et al. [18] experimentally indicated that ice shedding tends to occur from the tip side. Therefore, if a cell is judged to be a shedding cell, we assume that all cells from the position of the cell to the tip of the rotor are shed simultaneously. Once ice shedding occurs, we repeatedly compute the flow field, the droplet trajectory, and the thermodynamics.

\section{Validation of the Proposed Method}

\subsection{Validation Conditions}

We validated the proposed icing method (i.e., the icing cell method) using a NACA0012 airfoil because there are significant experimental data on this airfoil in the literature. In the present study, the overset grid method is used to clarify the icing area around the leading edge, where the icing phenomenon frequently occurs. The computational grid system is shown in Fig. 3. The icing cell method appeared to be sensitive to the sub-grid resolution. Therefore, we investigated three sub-grids having different grid resolutions: a coarse grid with a resolution of $181 \times 41$, a medium grid with a resolution of $241 \times 71$, and a fine grid with a resolution of $301 \times 101$. The total numbers of grid points included in the main grid for these resolutions are 23,112,

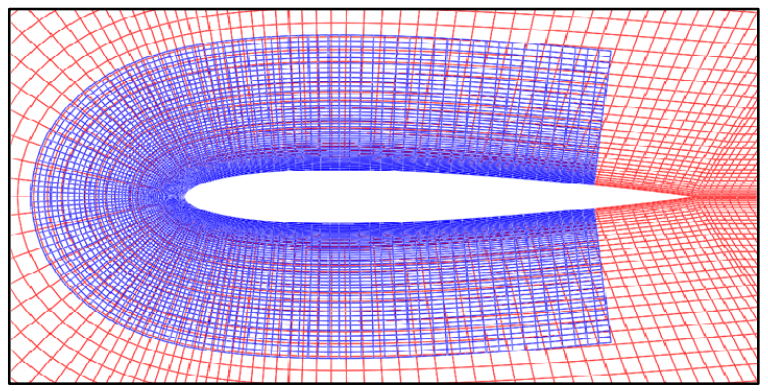

Fig. 3 Computational grids used in the validation (red: main grid; blue: sub-grid).

32,802 , and 46,092, respectively. The computational domain is 20 chord $\times 20$ chord. The validation conditions are listed in Table 1. These conditions are for the rime ice, which occurs at the very cold atmospheric temperature.

\subsection{Validation Results}

The computational results predicted by the present method were compared to the results by our previous method, the computational results by NASA, and the experimental data measured by NASA [1]. The ice shape near the leading edge is shown in Figs. $4 a-4 c$ for the coarse, medium, and fine grids, respectively. The ice shape and the icing area obtained using the proposed method are approximately the same as the others. In addition, in the proposed method, the grid resolution appears to have little effect on the icing simulation. These results confirm that icing simulation using the icing cell method is reasonable.

\section{Computational Conditions}

\subsection{Computational Target and Grids}

The computational target is a commercial axial blower (Showa Denki Co. Ltd., Kairyu series A2D6H-411) because there is no experimental data of the ice shedding in a jet engine. This axial fan was used in the experimental study (Murooka et al. [13], see Fig. 5). This axial fan has 12 rotor blades, although, for simplicity, only one rotor blade is simulated, under the assumption of geometrical periodicity. The computational grid, which is based on an overset grid method, is shown in Fig. 6a and is the main grid for the 


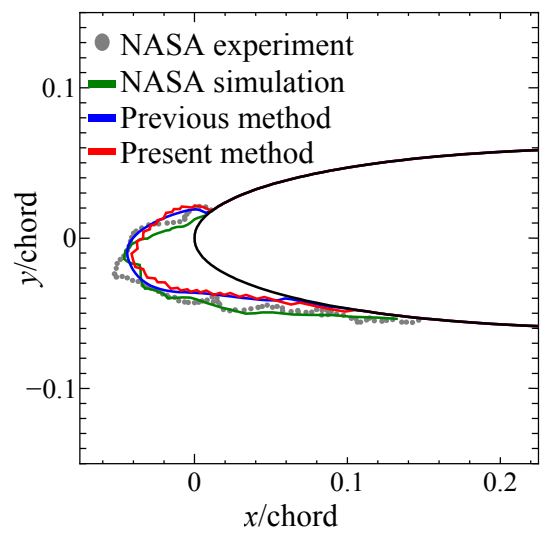

(a) Coarse grid

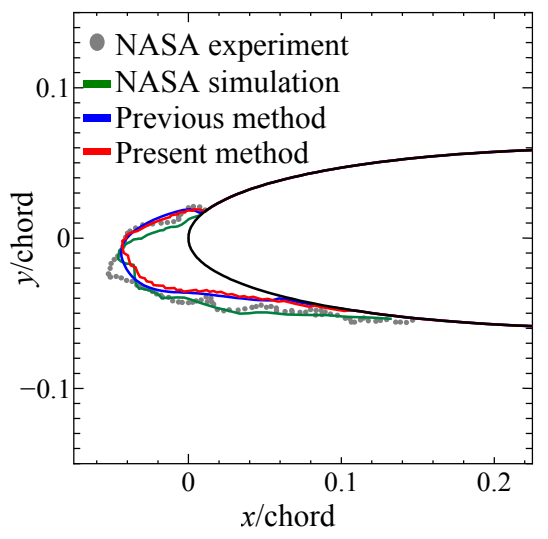

(b) Medium grid

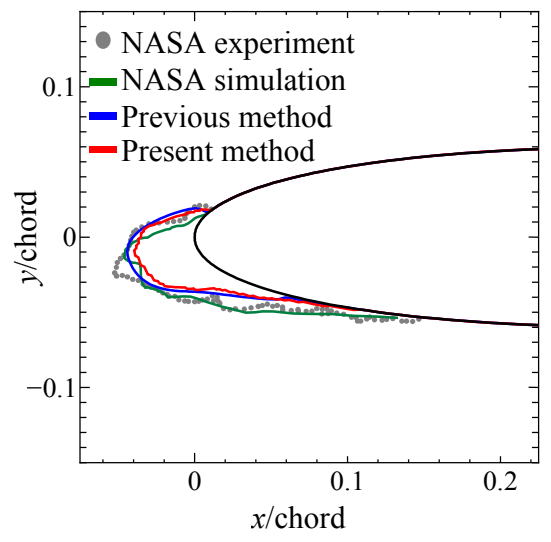

(c) Fine grid

Fig. 4 Comparison of icing shapes used in the validation.

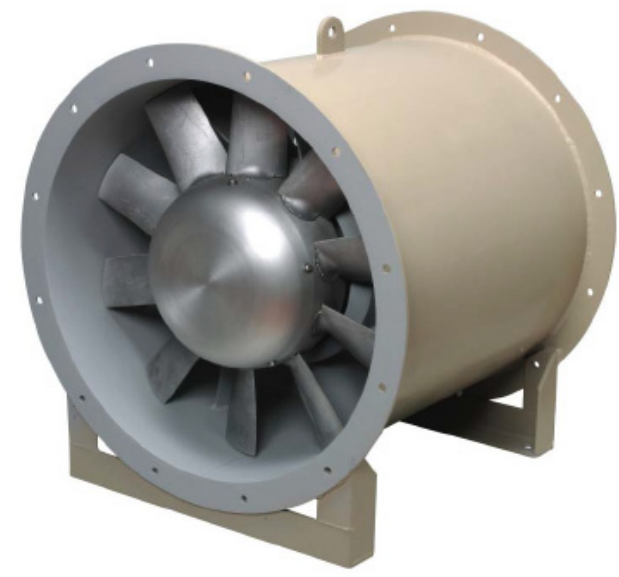

Fig. 5 Computational target.

Table 2 Computational conditions.

\begin{tabular}{lll}
\hline Rotating speed & $(\mathrm{rpm})$ & 1,800 \\
Mass slow rate & $(\mathrm{kg} / \mathrm{s})$ & 5.21 \\
Static temperature & $(\mathrm{K})$ & 268.15 \\
LWC & $\left(\mathrm{g} / \mathrm{m}^{3}\right)$ & 1.54 \\
MVD & $(\mathrm{m})$ & 30 \\
Exposure time & $(\mathrm{s})$ & 480.0 \\
\hline
\end{tabular}

passage. Fig. $6 \mathrm{~b}$ shows the sub-grid around the blade. Fine cells are set around the leading edge and the pressure side of this sub-grid, because the ice layer is easily formed there. The total number of grid points is $6,272,284$.

\subsection{Computational Condition}

The computational conditions used in the present study are listed in Table 2 . The droplet trajectory simulation is conducted for 500,000 droplets that were

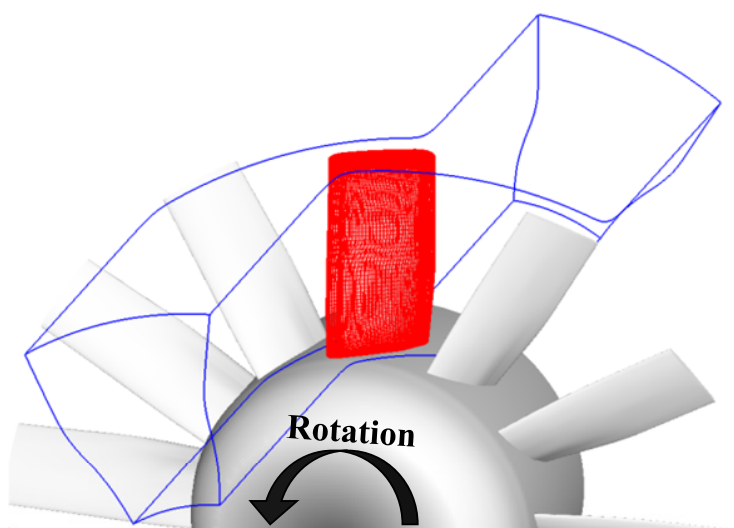

(a) Overview of the computational grid

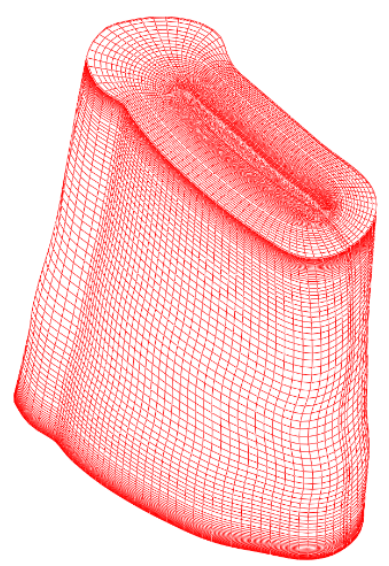

(b) Enlarged view of the sub-grid

Fig. 6 Computational grids.

randomly distributed at the upstream boundary. The initial droplet velocity is equal to the local gas velocity, which is obtained from the flow field computation. The total pressure, total temperature, and flow angle are imposed, and the Mach number is extrapolated at the 
upstream inflow boundary. The inflow turbulent kinetic energy is assumed based on $0.1 \%$ turbulence of the free stream. Adiabatic, no-slip conditions and the wall function are prescribed for the stationary walls and the rotating surfaces. The exit static pressure is specified.

\section{Results and Discussion}

\subsection{Static Temperature and Local Water Distribution}

The static temperature and the local water distribution on the blade surface are shown in Figs. 6 and 7, respectively. "L.E." means the leading edge, and "T.E." means the trailing edge. These two parameters are of great importance in icing simulation. The surface temperature is below the freezing point except at the blade tip on the pressure side, as shown in Fig. 6. Most

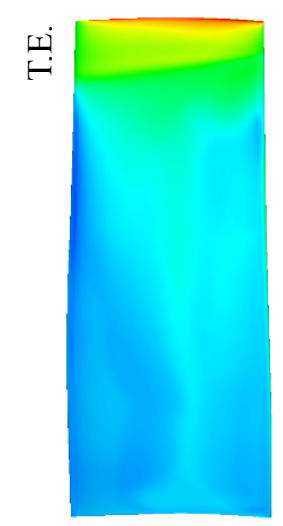

(a) Pressure side

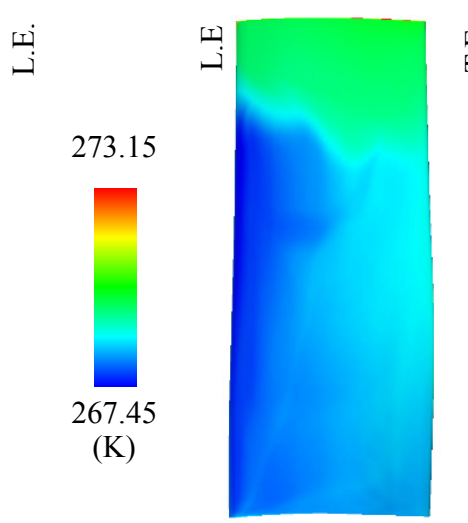

(b) Suction side
Fig. 7 Static temperature.

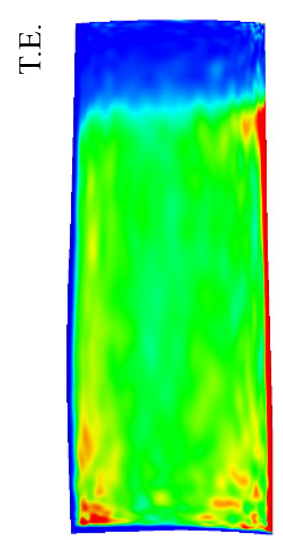

(a) Pressure side

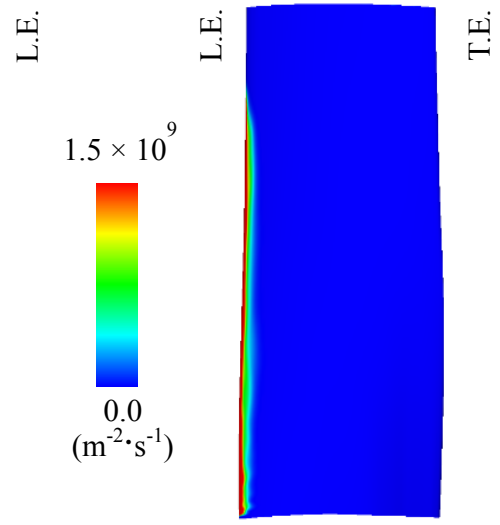

(b) Suction side
Fig. 8 Local water distribution. droplets impinge on the pressure side, particularly around the leading edge. Ice layers are expected to form in such areas because the surface temperature is below the freezing point.

\subsection{Ice Growth and Ice Shedding}

Fig. 8 shows the ice growth and ice shedding on the

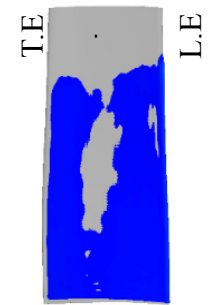

(a) $10 \mathrm{~s}$

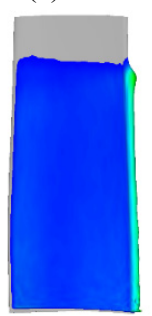

(e) $50 \mathrm{~s}$

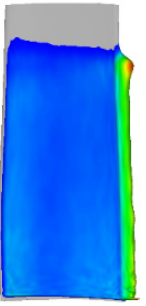

(i) $90 \mathrm{~s}$

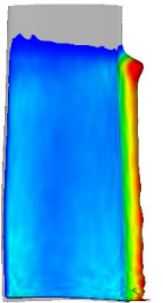

(m) $130 \mathrm{~s}$

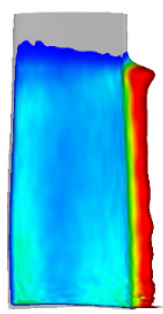

(q) $170 \mathrm{~s}$

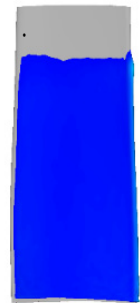

(b) $20 \mathrm{~s}$

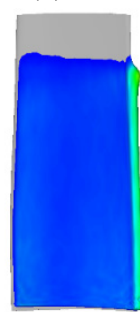

(f) $60 \mathrm{~s}$

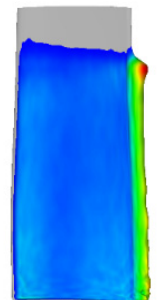

(j) $100 \mathrm{~s}$

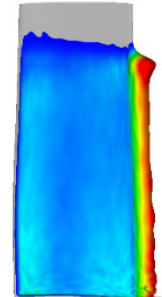

(n) $140 \mathrm{~s}$

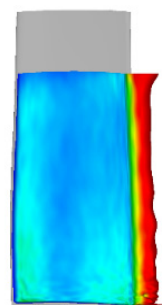

(r) $171 \mathrm{~s}$

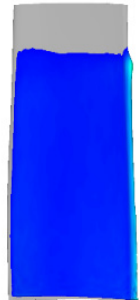

(c) $30 \mathrm{~s}$

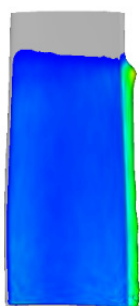

(g) $70 \mathrm{~s}$

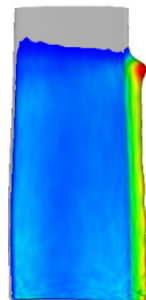

(k) $110 \mathrm{~s}$

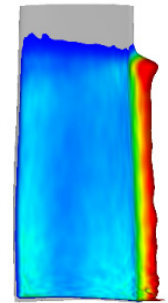

(o) $150 \mathrm{~s}$
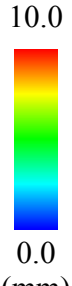

$(\mathrm{mm})$

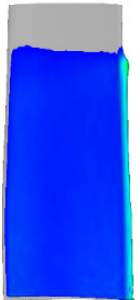

(d) $40 \mathrm{~s}$

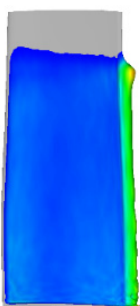

(h) $80 \mathrm{~s}$

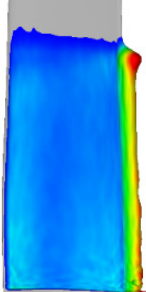

(1) $120 \mathrm{~s}$

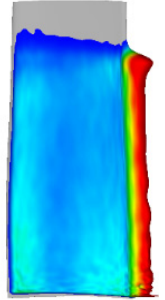

(p) $160 \mathrm{~s}$
Fig. 9 Temporal evolution of the ice layer on the pressure side. 


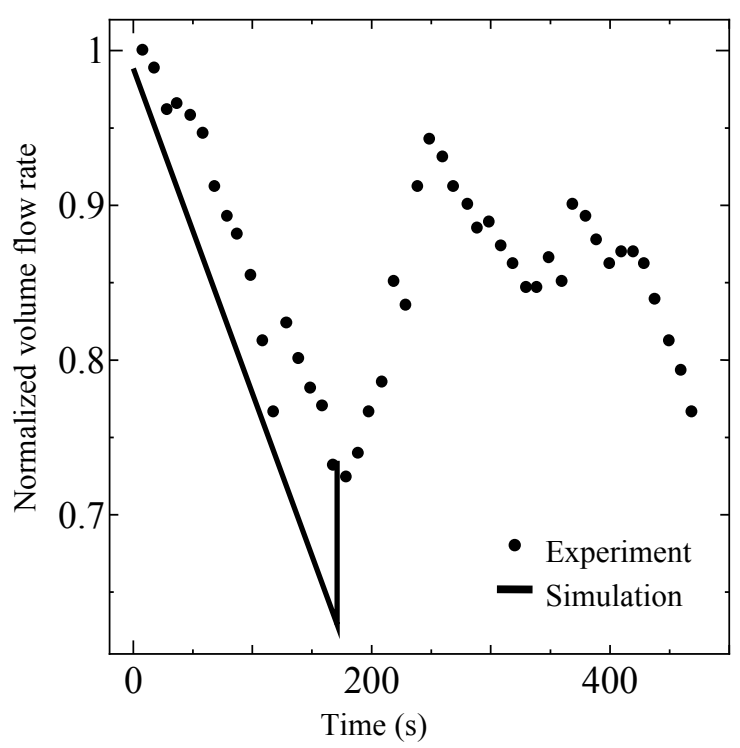

Fig. 10 Change of volume flow rate.

pressure side. The ice accretion is concentrated on the leading edge, at which the temperature falls to the freezing point and the local water distribution is sufficiently high, as mentioned above. Ice shedding occurs 171 seconds after ice growth begins. The position at which ice shedding occurs is near the leading edge at $71 \%$ of span, where a relatively strong centrifugal force acts on the ice layer and thus thick ice accretes. This tendency of ice shedding from the blade tip is similar to the experimental results reported by Brouwers et al. [18].

Finally, the flow rate change due to the ice growth and the ice shedding is shown in Fig. 9. The volume flow rate in Fig. 10 is normalized by the initial volume flow rate of the experiment. In the experiment, ice shedding occurred 179 seconds after the start of the test. The predicted time of ice shedding occurrence was 171 seconds. Thus, the estimation of the ice shedding obtained using the proposed method is reasonable. However, the recovery rate is considerably lower than that of the experiment. In the experimental study, the decrease in the flow rate due to ice growth was $27.6 \%$ before the first ice shedding, and the recovery was $21.8 \%$ after ice shedding. On the other hand, the flow rate decrease in the present study was $34.4 \%$, and the flow rate recovery was $10.6 \%$. This is thought to be due to the difference in the ice shedding volume. In the experiment, the flow rate after ice shedding was $94.3 \%$ of the initial flow rate, which means that larger ice pieces were shed from the rotor blade. Moreover, we simulated only the initial ice shedding. In the experiment, the volume flow rate recovers gradually after the initial ice shedding occurs, because ice shedding occurs more than once. Therefore, we need to run the simulation for a longer time until ice shedding occurs several times.

The present study confirmed that the proposed ice shedding model has high predictive performance for the ice shedding time. However, the model still includes a large error for the ice shedding volume.

\section{Conclusions}

We have developed a new icing simulation model that can reproduce both the ice growth and the ice shedding phenomena and validated the proposed model by comparing the obtained flow rate change due to ice growth and ice shedding to experimental data for an axial fan. The main results of the present study are as follows:

(1) The proposed ice shedding model has high predictive performance for the occurrence time of ice shedding.

(2) The proposed ice shedding model has an error for the flow rate recovery due to ice shedding because the volume of the piece of ice in the model was lower than that shed in the experiment.

In the future, we intend to improve the present ice shedding model for accurately predicting the ice shedding volume. In addition, we intend to add an ice-piece tracking model. Finally, we intend to apply the proposed icing simulation model to a rotor-stator interaction field in a jet engine.

\section{Acknowledgments}

The ice adhesion force and the flow rate change due to icing were obtained experimentally by T. Murooka (IHI Corporation), S. Shishido (IHI Corporation), R. 
Hiramoto (Hokkaido Institute of Technology), and T. Minoya (Hokkaido Institute of Technology). The present study was supported in part by JSPS KAKENHI Grant Number 25286101.

\section{References}

[1] Wright, W. B., Gent, P. W., and Gufford, D. 1997. DRA/NASA/ONERA Collaboration on Icing Research. NASA Contractor report.

[2] Veres, J. P., Jorgenson, P. C. E., and Wright, W. B. 2011. Modeling the Effects of Ice Accretion on the Low-Pressure Compressor and the Overall Turbofan Engine System Performance. Technical report.

[3] Nilamdeen, S., and Habashi, W. G. 2009. "FENSAP-ICE: Modeling of Water Droplets and Ice Crystals." In Proceeding of the 1st AIAA Atmospheric and Space Environments Conference, 600-10.

[4] Presteau, X., Montreuil, E., Chazottes, A., and Vancassel, X. 2009. "Experimental and Numerical Study of Scallop Ice on Swept Cylinder." In Proceedings of the 1st AIAA Atmospheric and Space Environments Conference, 563-78.

[5] Ozgen, S., and Canıbek, M. 2009. "Ice Accretion Simulation on Multi-element Airfoils Using Extended Messinger Model." Heat and Mass Transfer 45 (3): 305-22.

[6] Hospers, J., and Hoeijmakers, H. 2011. Numerical Simulation of SLD Ice Accretions. SAE Technical Paper.

[7] Aliaga, C. N., Aubé, M. S., Baruzzi, G. S., and Habashi, W. G. 2011. "FENSAP-ICE-Unsteady: Unified In-flight Icing Simulation Methodology for Aircraft, Rotorcraft, and Jet Engines." Journal of Aircraft 48 (1): 119-26.

[8] Hayashi, R., Kawakami, K., Suzuki, M., Yamamoto, M., Shishido, S., Murooka, T., and Miyagaw, H. 2011. "Numerical Simulation of Icing Phenomena in Fan Rotor-Stator Interaction Field." In Proceedings of the 11th
International Gas Turbine Congress, 1-5.

[9] Jeanne, G., Mason, J., Strap, W., and Chow, P. 2006. "The Ice Particle Threat to Engines in Flight." In Proceedings of the 44th AIAA Aerospace Sciences Meeting and Exhibit, 2445-65.

[10] Veillard, X., and Habashi, W. G. 2011. "Icing Simulation in Multistage Jet Engine." Journal of Propulsion and Power 27 (6): 1231-7.

[11] Papadakis, M., Yeong, H., and Suares, I. G. 2007. "Simulation of Ice Shedding from a Business Jet Aircraft." In Proceedings of the 45th AIAA Aerospace Sciences Meeting and Exhibit, 1-25.

[12] Baruzzi, G., Lagace, P., Aube, M., and Habashi, W. G. 2007. "Development of a Shed-Ice Trajectory Simulation in FENSAP-ICE." In Proceedings of SAE International Conference on Aircraft and Engine Icing, 3360-1.

[13] Murooka, T., Shishido, S., Hiramoto, R., and Minoya, T. 2011. "Surface Coating Effect on Protection of Icing for Axial Fan Blade." In Proceedings of SAE International Conference on Aircraft and Engine Icing, 1-6.

[14] Kato, M., and Launder, B. E. 1993. "The Modeling of Turbulent Flow around Stationary and Vibrating Square Cylinder." In Proceedings of the 8th Symposium on Turbulent Shear Flows, 1-6.

[15] Yee, H. C. 1987. Upwind and Symmetric Shock-Capturing Schemes. Technical report.

[16] Fujii, K., and Obayashi, S. 1987. "Practical Application of Improved LU-ADI Scheme for the Three-Dimensional Navier-Stokes Computations of Transonic Viscous Flows.” AIAA Journal 25: 369-70.

[17] Messinger, B. L. 1953. "Equilibrium Temperature of an Unheated Icing Surface as a Function of Airspeed." Journal of the Aeronautical Sciences 20 (1): 29-42.

[18] Brouwers, E. W., Palacios, J. L., Smith, E. C., and Peterson, A. A. 2010. "The Experimental Investigation of a Rotor Hover Icing Model with Shedding." In Proceedings of American Helicopter Society the 66th Annual Forum, 1-17. 